\section{Sir Harry Kroto (1939-2016): In memory}

$\mathrm{W}$ ith the passing of Harry Kroto, we have lost a great friend of science, admired by a large community of scientists, teachers, and students. He had been affected by a neural disorder, but remained active until recently. When a special symposium to mark the 30th anniversary of the discovery of fullerenes was held in London in July 2015, Harry was there, presenting a lecture-fully engaged. No one could have guessed that the end would come so soon.

I have known Harry for many years. We were both spectroscopists in the early days, and I used to see Harry at spectroscopy meetings. As a spectroscopist, he became interested in looking at long-chain carbon molecules; he felt such molecules existed in outer space. He visited the laboratory of Richard Smalley in Texas to look for such molecules in carbon vapor employing mass spectrometry. This resulted in the discovery of $\mathrm{C}_{60}$ and $\mathrm{C}_{70}$ and the fullerene family of carbon. The discovery of fullerenes changed carbon chemistry. It added a new dimension to nanoscience. It also became a popular and exciting field of research. The article on fullerenes published by Kroto et al. (Kroto, Heath, O'Brien, Curl, Smalley, Nature 318, 162 [1985]) is one of the most cited in chemistry. Let us not forget that carbon nanotubes, which later became the subject of significant research, are extended fullerenes. The current explosion in carbon nanoscience research, including graphene, has roots in this discovery of fullerenes.

His family came to the UK as refugees from Germany in the 1930s. Harry was born in Wisbech in Cambridgeshire on October 7, 1939, in the first month of World War II. The family later moved to Bolton, where Harry grew up and went to school. He attended The University of Sheffield for his undergraduate degree and, subsequently, carried out research for his PhD degree with Richard Dixon. He then went to the National Research Council, Canada, and Bell Laboratories in the United States for postdoctoral work. Harry took a faculty position at the University of Sussex after returning to Britain and became a professor in 1985. He raised the level of science in Sussex, contributing to various aspects of research and education at the university. The discovery of fullerenes made him and the university famous.

Harry received the 1996 Nobel Prize in Chemistry along with Richard Smalley and Robert Curl. He was a

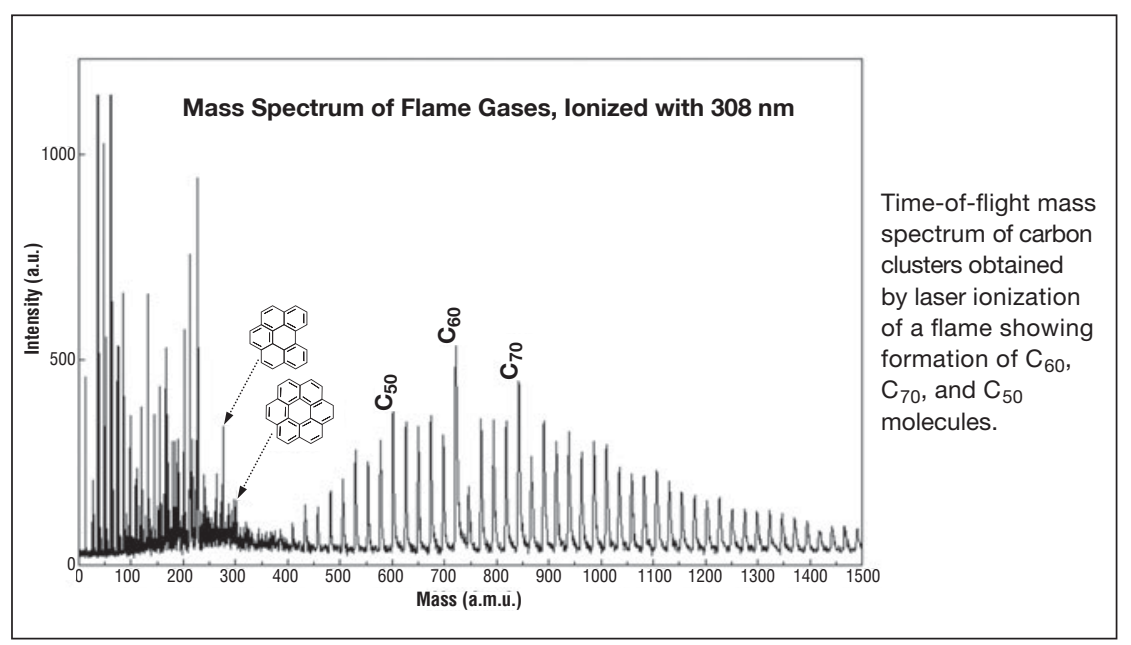

Fellow of The Royal Society and was a Royal Society Research Professor. He also received many other honors, including the Copley Medal of The Royal Society. He was knighted in 1996.

Science communication was one of his main missions, particularly in the last few years of his life. Harry's interest in science communication for the younger generation as well as for common citizens was contagious. His contributions to this activity are truly remarkable. He was a great communicator and a showman and gave wonderful lectures to children. He was partly responsible for the creation of the Vega Science Trust to produce science films for television. Harry was also outspoken on many issues related to society and humanity.

Harry passed away on April 30, 2016. $\mathrm{He}$ is survived by his wife Margaret and two sons.

\section{C.N.R. Rao}

National Research Professor and Linus Pauling Research Professor \& Honorary President, Jawaharlal Nehru Centre for Advanced Scientific Research in Bangalore, India. 